\title{
The Effect of Inclusion and Exclusion Indexes Towards LQ45 and MSCI Index on the Pattern of Stock Return and Stock Trading Volume
}

\author{
Kadek Ary Widyawati ${ }^{1}$, Buddi Wibowo ${ }^{2}$ \\ \{ary.widyawati@gmail.com ${ }^{1}$, buddi.wibowo@ui.ac.id ${ }^{2}$ \}
}

Faculty of Economics and Business, University of Indonesia ${ }^{1}$, Faculty of Economics and Business, University of Indonesia ${ }^{2}$

\begin{abstract}
This study examines the effect of changes in composition of the index on stock return and trading volumes at IDX used event study methodology. It is used to find out the market's response to inclusion or exclusion stocks of the LQ45 and MSCI indexes. The final sample consisted of 24 inclusion stocks and 22 exclusion stocks in the LQ45 index; 17 inclusion stocks and 10 exclusion stocks in the MSCI index. The result showed a significant increase (decrease) in return when a stock added to (deleted form) the LQ45 and MSCI indexes. It also obtained a significant result in trading volume from inclusion and exclusion stocks in the MSCI index, yet inclusion stocks in the LQ45 index was not. This shows that the Indonesian capital market is not fully efficient market. This research supports the sustainability of investors' investment because it can be used as recommendations of making investment decisions.
\end{abstract}

Keywords: Event study, index changes, LQ45 Index, MSCI Index.

\section{Introduction}

The investors which invested in the capital market obviously have several considerations in deciding which company would be chose to minimalize the risk that probably appear. Moreover, the number of public companies that currently listed in Indonesia Stock Exchange (IDX) is pretty much. This is would be difficult for the investors if they have to observe the movement of stocks' companies listed in IDX. Generally, the investors which is doing transaction in the capital market should be based on a market index.

Nowadays, there are 34 stock indexes in IDX. The indexes classified into 4 groups such as headline index, sector index, thematic index, and factor index. Headline index is an index which used as the main reference to describe the performance of the capital market. Headline index is classified into 4 sub classification such as composite, board, liquidity and liquidity co-branding. From all indexes of the sub classification, Liquid 45 index in short LQ45 has one-year return in 2018 until 2019 that classified as the highest index than the 
others which is $3.2 \%$. LQ45 index is an indicator to show the price performance of 45 highest liquidity stocks, has a large market capitalization, and also supported by good company fundamentals. Relating to the point, so there are many local investors use LQ45 index as the main reference.

Currently, there is not only local investors which invested in the Indonesia capital market. Yet, the foreign investors also have a significant role in the movement of Indonesia capital market. It is can be seen on Table 1 where the foreign transaction value relatively bigger than the transaction value of local investors, exactly in the first semester of 2019, the foreign transaction value is $52,22 \%$ and $51,85 \%$ in the second semester of 2019. As same as the local investor, foreign investors which invested in Indonesia usually use index reference and the global index is chosen. The global index that most frequently used is creating by Morgan Stanley namely Morgan Stanley Capital International index in short MSCI. Nowadays, Indonesia entered as the constituent in MSCI Emerging Market Index that divided into 2 indexes such as MSCI Global Small Cap Indexes and MSCI Global Standard Index. The MSCI index can be described as the actual buying opportunities for global investors which considers the limiting factor of the stock exchange of a country related to the foreign stock-ownership. In other words, the stocks included in the MSCI index list are the stock with a large portion of foreign ownership and liquid than other stocks. Stocks in the MSCI index have indicators used as the main requirement which is having fundamental, liquidity, and good market capitalization.

Table 1. Stock-Ownership Composition

\begin{tabular}{|c|c|c|c|c|}
\hline \multirow{2}{*}{ Period } & \multicolumn{4}{|c|}{ Stock-Ownership Composition (IDR) } \\
\cline { 2 - 5 } & \multicolumn{2}{|c|}{ Value (Rp Billion) } & \multicolumn{2}{c|}{$\%$ Value } \\
\cline { 2 - 5 } & Local & Foreign & Local & Foreign \\
\hline Semester I-2019 & $1.773 .303,53$ & $1.937 .894,97$ & $47,78 \%$ & $52,22 \%$ \\
\hline Semester II-2019 & $1.796 .464,24$ & $1.934 .279,64$ & $48,15 \%$ & $51,85 \%$ \\
\hline
\end{tabular}

This study focused on the stocks that are announcing to have inclusion and exclusion from the LQ45 and MSCI index. These stocks will be evaluated for the changes in price and the trading volume. Indeed, the price changes affected the return that is obtained by investors. LQ45 index considered the right tool for domestic investors because it is 45 of the most liquid stocks in Indonesia. However, MSCI index is an alternative and comparison used by local and global investors. 
Several similar studies have been conducted by Wilkens and Wimschulte [1]; Bechmann [2]; Shankar and Miller [3]; and Hung and Shiu [4] which gave similar results, that there were significant changes to the stock price when the stock included or excluded into the reference of index. On the other hand, Chen, Koutsantony [5] showed that there was an impaction to the stock price when inclusion and exclusion stocks of the reference index was not giving any significant affect. While Chen, Shiu [6] found a result that the impaction of stock price when it obtained inclusion or exclusion of the reference index, however, the effect was temporary.

The aim of the present study was to find out the evidence of whether there is an effect of price changes when stocks were included or excluded from the reference indexes of LQ45 and MSCI. The changes in composition of the LQ45 index announced every 6 months. While the announcement of changes in composition of the MSCI index was every 3 months. Allegedly, when a stock was included to the LQ45 or MSCI index composition, the price and trading volume of the stock was getting increases. On the contrary, when a stock was excluded from the LQ45 or MSCI index composition, the price and trading volume will get down. As the result, the present study constructed two research questions as follows: (1) whether the announcement of the inclusion or exclusion stock from the LQ45 and MSCI index will affect the stock price around the announcement date. (2) whether the announcement of the inclusion or exclusion stocks from the LQ45 and MSCI index will be increasing or decreasing the trading volume of stock that included and excluded to the LQ45 and MSCI index around the announcement date.

In order to discover the market reaction towards the announcement of index composition changes, thus a market efficiency test is conducted. Testing whether there is a market reaction to the announcement arranged by event study method. It is used to learn the reaction of market on the event where the information published as an announcement [7]. If there is an announcement containing information, so the market predicted would be responding while the announcement received. Most of the empirical studies revealed that when a stock includes to the index, there will be a significance affect to the stocks return, in other words, the market positively responds the stocks announcement that included to the stocks and vice versa. The stocks announcement that included or excluded from an index is something interesting to be analyzed using event study. By using the event study method in this research, investors will be able to find out the effect of changes in composition of the LQ45 and MSCI index on the stock price and stock trading volume, therefore, this research can support the sustainability of investors' investment in the capital market because it provides indicators that can be used as recommendation for investors 
regarding to decision of buy, hold or even sell the stocks while LQ45 and MSCI index got composition changes. Besides, the present study also can be used as the consideration by issuers listed in IDX to keep the performance of their stock company.

This research will be divided into 5 parts. The first part will discuss about the issues raised. The second part will review the theoretical used in this present study including the previous studies. Then, the third part will discuss about the research methodology. The fourth part will test the data obtained. The last part which the fifth is the conclusion of the present study.

\section{Literature Review}

Prices never fully reflect all the information that can be collected and followed up by informed traders [8]. If the market can react quickly and accurately in order to reach the new equilibrium prices that wholly reflect the existing information, then market conditions like this are called efficient markets [7]. On the other hand, if stock price motion can be predicted, it would be the indication of inefficiency the stock market, since the prediction of prices will indicate all existing information which have not been reflected in stock prices. Therefore, the idea of stocks reflects all existing information named as the hypothesis of efficient market [7].

The key to measuring an efficient market is the relationship between securities price and information [9]. Fama [10] divides types of market efficiency based on past information, current information that is being collected and private information. Strong, semi-strong and weak are categorized as the forms market efficiency. The weak form of market efficiency characterized by current stock prices that fully reflects all information about two things, they are past price records and past transaction volumes. The market efficiency in semistrong forms is reflecting if current stock prices describe the past prices, transaction volumes, and publishing information. Whereas in the form of strong market efficiency, current stock prices reflect four things, they are price records, transaction volumes, publishing information, and private information.

In the present research, a semi-strong form of market efficiency testing was conducted using the event study method. The use of event study is to learn the market reaction into an occasion in which information is published as an announcement. If an announcement is fraught with information, therefore, the market predicted will be reacting when the market receives the announcement. The announcement of the inclusion and exclusion of stock indexes is a very interesting thing to be reviewed using the event study. 
Most empirical studies showed that the inclusion stocks in the index were produced a significant enhancement in the price and volume of trading stocks. On the other hand, stocks that got exclusion from the index cause a reduction in stock prices and trading volume. Kassim, Ramlee [11] tested the impact of inclusion (or exclusion) on stock prices and trading volume. The results of these studies indicate that stocks included into the EMAS Shariah Index will provide a significant permanent return as well as abnormal volume. Whereas the exclusion stocks produce a negative significant temporary return, and the trading volume was below the normal level.

Shu, Yeh [12] conducted a study about the stocks' prices and volumes of public companies listed in Taiwan. The research focused on the inclusion and exclusion stocks from the MSCI index. The focus of this study is to examine event studies in order to find out an abnormal increase in returns when the stocks were included or excluded from the MSCI index. The results of this study illustrated the positive relationship between returns and the inclusion stocks into the MSCI index, while the exclusion stock from the MSCI index proved to have a negative relationship with returns. Besides Shu, Yeh [12], Hung and Shiu [4] also conducted a study on changes in the composition of the MSCI index in Taiwan. Data analysis used multivariate analysis in order to calculate the abnormal returns. This study found that when stocks were included into the MSCI index, thus, transaction activity, foreign ownership, and stock prices were getting enhancement. Whereas when the stocks were excluded from the MSCI index list, the consequence is that the stock prices and foreign ownership were getting a reduction.

Chakrabarti, Huang [13] also researched inclusion and exclusion stocks in the MSCI index, where according to the observation through stocks included into the index, were giving positive abnormal returns; however, the stocks excluded from the index were giving negative abnormal returns. Furthermore, Chen, Shiu [6] established a study in order to obtain evidence of whether the inclusion and exclusion of stocks from the MSCI index were linearly affected on stock prices and investor interests. This study gained proof that abnormal results and excessive trading volume was associated with composition changes of the MSCI index. In addition, abnormal returns are positively associated when the compilation of stocks was included to the index composition, and it negatively associated when they were deleted from index composition. However, the price rises or falls temporarily.

Other studies focused on finding empirical evidence of the effect of announcements and implementation of index changes on stock prices and volumes, and it was a research conducted by Wilkens and Wimschulte [1]. Their research showed a positive abnormal return and a reduction in transaction 
volume around the announcement day. Whereas in the implementation of index changes showed a positive abnormal return but the transaction volume relatively varies.

\section{Data and Methodology}

\subsection{Data}

The data obtained in this research is secondary data consisting of daily stock's prices and trading stock volume companies listed in the Indonesia Stock Exchange obtained by Eikon. The data divided in two parts such as the inclusion and exclusion stocks of companies from the LQ45 in period of February 2015 until November 2019 and the inclusion and exclusion stocks of companies from MSCI index in period of February 2010 until November 2019. The information about inclusion and exclusion stocks of companies from LQ45 index was obtained from the website of Indonesian Stock Exchange, however, the information about inclusion and exclusion stocks of companies from MSCI was obtained from the website of MSCI. The companies used as sample of the present research may not have other events occurred in the internal of company both in the window period and estimation period, such as dividend announcements, IPOs and stock split. When one of the samples was experiencing those events, they will be excluded from the sample of research. The final sample of present research consisted of 24 stocks which have inclusion and the other 22 stocks have exclusion in LQ45 index, on the other hand, there were 17 stocks which have inclusion and 10 stocks have exclusion in MSCI index. Regarding the number of samples which showed in detail on Table 2.

Table 2. Number of Research Samples

\begin{tabular}{|c|c|c|c|c|}
\cline { 2 - 5 } \multicolumn{1}{c|}{} & \multicolumn{2}{c|}{ LQ45 Index } & \multicolumn{2}{c|}{ MSCI Index } \\
\cline { 2 - 5 } \multicolumn{1}{c|}{} & Initial & Final & Initial & Final \\
\hline Inclusion & 31 & 24 & 24 & 17 \\
\hline Exclusion & 31 & 22 & 18 & 10 \\
\hline Total & 62 & 46 & 42 & 27 \\
\hline
\end{tabular}

\subsection{Methodology}

\subsubsection{Stock Price Effect}


In order to find out the effect of announcement of stock composition changes in LQ45 index and MSCI index on stock prices, the abnormal return is calculated from the stocks. There are steps of calculating the abnormal return as follows:

1) Calculating realized return/real return [9]

$$
R_{i, t}=\frac{P_{i, t}-P_{i, t-1}}{P_{i, t-1}}
$$

where $R_{i, t}$ represents the realized return for the security $i$ in the event period $t ; P_{i, t}$ represents the stock closing price of company $i$ in event period $t$; and $P_{i, t-1}$ is the stock closing price of company $i$ in event period $t-1$.

2) Calculating daily expected return of stock, it used the market model with the following formula as follows [14]:

$$
R_{i, j}=\alpha_{i}+\beta_{i} R_{M J}+\varepsilon_{i, j}
$$

where $R_{i, j}$ is the realized return for security $i$ in estimation period $j ; \alpha_{i}$ is the intercept for security $i ; \beta_{i}$ represents the slope coefficient which is Beta from security $i$; and $R_{M J}$ is the market index returns on estimation period $j$.

After the score has been obtained, the step is continued to form an estimation model

$$
E\left(R_{i, t}\right)=\alpha_{i}+\beta_{i} E\left(R_{M J}\right)
$$

where $E\left(R_{i, t}\right)$ represents the expected return for security $i$ on event period $t$.

3) Calculating abnormal return which is formulated as follows

$$
A R_{i, t}=R_{i, t}-E\left[R_{i, t}\right]
$$

where $A R_{i, t}$ represents the abnormal return on security $i$ on event period $t$.

4) Calculating the average of abnormal return

The abnormal return test was not to do for each security, but it was carried out aggregately by testing the average of abnormal result in all securities by cross-section for all days in event period. The average of abnormal return for $t$-day can be calculated based on the average of arithmetic as follows [14]

$$
A A R_{t}=\frac{\sum_{i=1}^{k} A R_{i, t}}{k}
$$

where $A A R_{t}$ represents the average of abnormal return on day $t$; and $k$ presents the total of securities effected by the announcement of event. 
5) After the average of abnormal return obtained, then, calculating the cumulative average abnormal return which as known as CAAR. CAAR is the sum of the average of past days in abnormal return on the event period [14].

$$
\operatorname{CAAR}_{\left(t_{1}, t_{p}\right)}=\sum_{t=t_{1}}^{t_{p}} A A R_{t}
$$

where $C A A R_{\left(t_{1}, t_{p}\right)}$ the average accumulation of abnormal return from day $t_{1}$ until day $t_{p}$

In order to test the statistical significance of CAAR which done by t-test. The null hypothesis is that the announcement of stock composition changes which has no effect on abnormal return. The t-test is given as follows [15]:

$$
t=\sqrt{N} \frac{\operatorname{CAAR}_{\left(t_{1}, t_{p}\right)}}{\hat{s}\left(\operatorname{CAAR}_{\left(t_{1}, t_{p}\right)}\right)}
$$

\subsubsection{Trading Volume Effect}

In order to do the changes investigation on trading volume, Harris and Gurel [16] used volume ratio $\left(V R_{i t}\right)$, for each security in event period $t$. There is the formula of volume ratio calculated as follows:

$$
V R_{i t}=\frac{V_{i t}}{V_{m t}} \times \frac{V_{m}}{V_{i}}
$$

where $V_{i t}$ is the trading volume of stock $i$ on day $t$ in the event period; $V_{m t}$ is the market trading volume on day $t$ in the event period; $V_{i}$ represents the average of stock $i$ trading volume on estimation period; and $V_{m}$ is the average of market trading volume on estimation period.

Next, calculation the mean volume ration cross-sectionally $\left(M V R_{t}\right)$ as follows:

$$
M V R_{t}=\frac{1}{N} \sum_{i=1}^{N} V R_{i t}
$$

In order to test the statistical significance from $M V R_{t}$, it was done by a twotailed t-test. Where the null hypothesis is that the announcement of stock composition changes has no effect on volume.

\section{Results}

In this section, it was shown the analysis result regarding the impact towards the announcement of inclusion and exclusion stocks changes from the LQ45 index and MSCI index to stock prices and stock trading volume. 


\subsection{Price Effects of Inclusion and Exclusion Stocks from LQ45 Index}

Table 3 and Table 4 showed that AAR and CAAR for inclusion and exclusion stocks from the LQ45 index around the event window or the day before the announcement reaching with the day after the announcement of changes in the LQ45 index. According to Table 3, it was found that for stocks which included in the LQ45 index, there were 7 positive AARs yet only 2 significant AARs on day- 0 or on the announcement of changes to inclusion stocks in LQ45, and the second day after the announcement released. It can be assumed that the announcement of changes to inclusion stocks in the LQ45 index significantly affects the stock prices; in the other words, the market gives a positive response to the announcement of inclusion stocks in the LQ45 index. In addition, there were 9 positive CAARs where significance CAAR occurred on the second day until the fifth day after the announcement of inclusion stocks in the LQ45 index. Although CAAR affected statistically significant since the second day until the fifth day after the announcement; However, there was a negative AAR on the fourth day and fifth day after the announcement. Therefore, the market's response was temporary for the changes.

Table 3. Significance test result from AAR and CAAR for inclusion stocks of the LQ45 Index

\begin{tabular}{|r|r|r|r|r|}
\hline \multirow{2}{*}{$\begin{array}{c}\text { Time } \\
(\mathrm{t})\end{array}$} & \multicolumn{4}{|c|}{ Inclusions } \\
\cline { 2 - 5 } & \multicolumn{1}{c|}{ AAR } & $t$-statistic & \multicolumn{1}{c|}{ CAAR } & $t$-statistic \\
\hline-5 & -0.0041 & -0.7983 & -0.0041 & -0.7599 \\
\hline-4 & -0.0019 & -0.3122 & -0.0060 & -0.6386 \\
\hline-3 & 0.0083 & 1.2601 & 0.0024 & 0.1684 \\
\hline-2 & -0.0008 & -0.1280 & 0.0015 & 0.0962 \\
\hline-1 & 0.0007 & 0.1228 & 0.0022 & 0.1412 \\
\hline 0 & 0.0264 & $2.4161 *$ & 0.0286 & 1.4144 \\
\hline 1 & 0.0061 & 0.8263 & 0.0347 & 1.5616 \\
\hline 2 & 0.0100 & $1.8123 *$ & 0.0447 & $2.0761 *$ \\
\hline 3 & 0.0070 & 1.5233 & 0.0517 & $2.2897 *$ \\
\hline 4 & -0.0083 & -1.8416 & 0.0434 & $1.9111^{*}$ \\
\hline 5 & -0.0016 & -0.2206 & 0.0418 & $1.7375^{*}$ \\
\hline *statistical significance at the 5\% level &
\end{tabular}




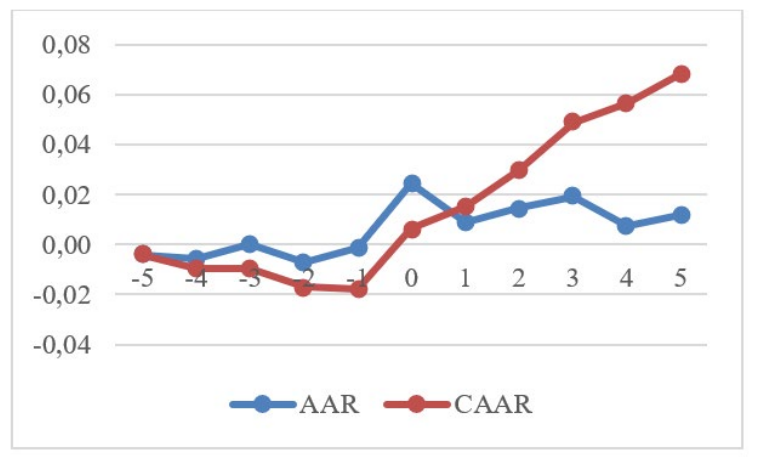

Fig. 1. Graphic movement of AAR and CAAR's inclusion stocks in the LQ45 index

Then, there were 7 negative AARs and 10 negative CAARs for the exclusion stocks in the LQ45 index showed in Table 4. From 7 negative AARs, there were 2 significant AARs on the second day before the announcement and a day after the announcement of changes to exclusion stocks in the LQ45 index. The negative and significant AAR showed that the market's response to the announcement was negative; In other words, the announcement of exclusion stocks from the LQ45 index gave a negative impact on the stock prices. On the other hand, the negative AAR on two days before the announcement showed that there was an anomaly. And looking for the CAAR, there was a negative and significant CAAR on two days before the announcement, also a day until 4 days after the announcement of exclusion stocks in the LQ45 index. Yet, on Table 4 exactly on the fifth day, there was a positive AAR. It means that the market's response was not as permanent as the index changes. It also can be proved by looking in Figure 1 and Figure 2, the result was very well obtained on the inclusion and exclusion of the LQ45 index which along with the result obtained by Bechmann [2] where generally, the exclusion stocks give a negative impact on the stock prices. However, the inclusion stocks to the indexes showed a positive impact on stock prices.

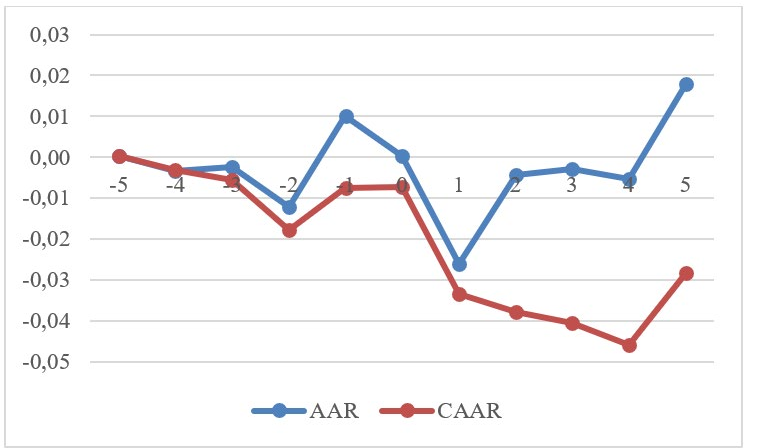

Fig. 2. Graphic movement of AAR and CAAR's exclusion stocks in the LQ45 index 
Table 4. Significance test result from AAR and CAAR for exclusion stocks of the LQ45 Index

\begin{tabular}{|r|r|r|r|r|}
\hline \multirow{2}{*}{$\begin{array}{c}\text { Time } \\
(\mathrm{t})\end{array}$} & \multicolumn{4}{|c|}{ Exclusions } \\
\cline { 2 - 5 } & AAR & $t$-statistic & \multicolumn{1}{c|}{ CAAR } & $t$-statistic \\
\hline-5 & 0.0002 & 0.0576 & 0.0002 & 0.0576 \\
\hline-4 & -0.0034 & -0.8341 & -0.0032 & -0.5015 \\
\hline-3 & -0.0023 & -0.5750 & -0.0055 & -0.7250 \\
\hline-2 & -0.0122 & $-2.6604 *$ & -0.0177 & $-2.0003 *$ \\
\hline-1 & 0.0102 & 1.5383 & -0.0075 & -0.6745 \\
\hline 0 & 0.0002 & 0.0324 & -0.0073 & -0.4866 \\
\hline 1 & -0.0261 & $-3.1658 *$ & -0.0334 & $-2.6650 *$ \\
\hline 2 & -0.0044 & -0.6549 & -0.0378 & $-2.3969 *$ \\
\hline 3 & -0.0029 & -0.4549 & -0.0407 & $-2.3188^{*}$ \\
\hline 4 & -0.0054 & -0.9731 & -0.0461 & $-2.5038^{*}$ \\
\hline 5 & 0.0178 & 1.4571 & -0.0283 & -1.6317 \\
\hline *statistical significance at the 5\% level \\
\hline \multicolumn{5}{|c}{}
\end{tabular}

\subsection{Price effects of inclusions and exclusions stocks from MSCI index}

The effect of inclusion and exclusion stocks in the MSCI index towards the return stocks pattern showed in Table 5 and Table 6 , where Table 5 and Table 6 showed the summarize of the calculation of AAR and CAAR from inclusion and exclusion stocks from the MSCI index around the date of the index composition changes announcement. However, Figure 3 and Figure 4 showed that the graphic movement of AAR and CAAR during the event window research. On the inclusion stocks in the MSCI index, there was a positive and significant AAR on a day after the index changes announcement. In line with the research done by Chakrabarti, Huang [13] who inferred that there was a positive abnormal return on a day after the date of composition changes announcement in the MSCI index.

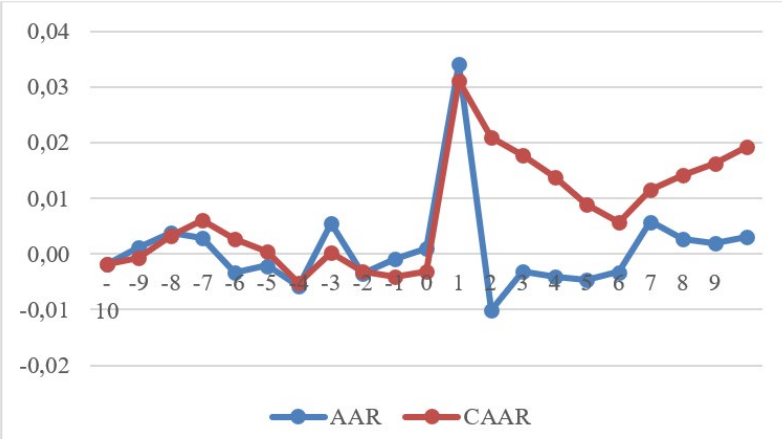

Fig. 3. Graphic movement of AAR and CAAR's inclusion stocks in the LQ45 index 
Table 5. Significance test result from AAR and CAAR for inclusion stocks of the MSCI Index

\begin{tabular}{|r|r|r|r|r|}
\hline \multirow{2}{*}{$\begin{array}{c}\text { Time } \\
(\mathrm{t})\end{array}$} & \multicolumn{5}{|c|}{ Inclusions } \\
\cline { 2 - 5 } & \multicolumn{1}{|c|}{ AAR } & $t$-statistic & \multicolumn{1}{c|}{ CAAR } & $t$-statistic \\
\hline-10 & -0.0018 & -0.3862 & -0.0018 & -0.3862 \\
\hline-9 & 0.0011 & 0.1966 & -0.0007 & -0.1041 \\
\hline-8 & 0.0039 & 0.8134 & 0.0032 & 0.3548 \\
\hline-7 & 0.0028 & 0.5472 & 0.0060 & 0.5352 \\
\hline-6 & -0.0034 & -0.6683 & 0.0026 & 0.1987 \\
\hline-5 & -0.0021 & -0.2893 & 0.0005 & 0.0318 \\
\hline-4 & -0.0057 & -0.7466 & -0.0052 & -0.2937 \\
\hline-3 & 0.0055 & 1.1757 & 0.0003 & 0.0163 \\
\hline-2 & -0.0035 & -0.5785 & -0.0032 & -0.1633 \\
\hline-1 & -0.0008 & -0.1160 & -0.0041 & -0.1833 \\
\hline 0 & 0.0010 & 0.1707 & -0.0031 & -0.1269 \\
\hline 1 & 0.0341 & $3.9078 *$ & 0.0310 & 1.1186 \\
\hline 2 & -0.0100 & -1.7107 & 0.0210 & 0.8258 \\
\hline 3 & -0.0032 & -0.6806 & 0.0177 & 0.6702 \\
\hline 4 & -0.0040 & -0.9633 & 0.0137 & 0.4954 \\
\hline 5 & -0.0047 & -0.7738 & 0.0089 & 0.2879 \\
\hline 6 & -0.0032 & -0.6934 & 0.0057 & 0.1735 \\
\hline 7 & 0.0058 & 1.5844 & 0.0115 & 0.3276 \\
\hline 8 & 0.0027 & 0.3163 & 0.0142 & 0.3586 \\
\hline 9 & 0.0020 & 0.3984 & 0.0162 & 0.4060 \\
\hline 10 & 0.0031 & 0.3556 & 0.0192 & 0.5158 \\
\hline & & & & \\
\hline
\end{tabular}

*statistical significance at the $5 \%$ level

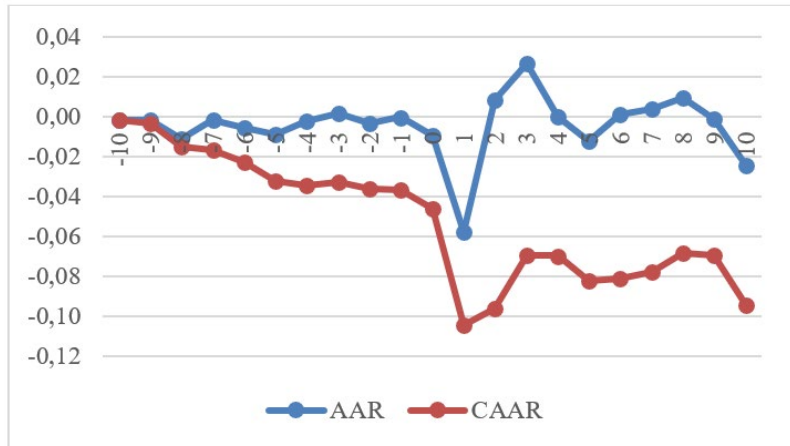

Fig. 4. Graphic movement of AAR and CAAR's exclusion stocks in the MSCI index 
Table 6. Significance test result from AAR and CAAR for exclusion stocks of the MSCI Index

\begin{tabular}{|r|r|r|r|r|}
\hline \multirow{2}{*}{$\begin{array}{c}\text { Time } \\
(\mathrm{t})\end{array}$} & \multicolumn{4}{|c|}{ Exclusions } \\
\cline { 2 - 5 } & AAR & $t$-statistic & \multicolumn{1}{c|}{ CAAR } & $t$-statistic \\
\hline-10 & -0.0017 & -0.2620 & -0.0017 & -0.2620 \\
\hline-9 & -0.0021 & -0.4411 & -0.0038 & -0.3855 \\
\hline-8 & -0.0115 & -1.2208 & -0.0153 & -1.1569 \\
\hline-7 & -0.0019 & -0.4979 & -0.0172 & -1.1333 \\
\hline-6 & -0.0060 & -0.8091 & -0.0232 & -1.0738 \\
\hline-5 & -0.0092 & -1.3428 & -0.0323 & -1.2158 \\
\hline-4 & -0.0022 & -0.2122 & -0.0345 & -1.1789 \\
\hline-3 & 0.0016 & 0.2061 & -0.0330 & -1.0508 \\
\hline-2 & -0.0034 & -0.2908 & -0.0364 & -1.4061 \\
\hline-1 & -0.0005 & -0.0409 & -0.0369 & -1.6403 \\
\hline 0 & -0.0096 & $-2.1924 *$ & -0.0465 & -1.8907 \\
\hline 1 & -0.0581 & $-5.7816 *$ & -0.1046 & $-3.6257 *$ \\
\hline 2 & 0.0081 & 0.5611 & -0.0964 & $-2.6369 *$ \\
\hline 3 & 0.0266 & 1.2305 & -0.0699 & -1.7586 \\
\hline 4 & -0.0001 & -0.0102 & -0.0700 & -1.6863 \\
\hline 5 & -0.0125 & -1.4853 & -0.0825 & -1.7871 \\
\hline 6 & 0.0009 & 0.0905 & -0.0816 & -1.5695 \\
\hline 7 & 0.0036 & 0.4012 & -0.0780 & -1.4145 \\
\hline 8 & 0.0091 & 0.7917 & -0.0688 & -1.0582 \\
\hline 9 & -0.0011 & -0.2170 & -0.0699 & -1.0728 \\
\hline 10 & -0.0248 & $-2.7708 *$ & -0.0947 & -1.4774 \\
\hline$*$ statistical significance at the 5\% level & & \\
\hline
\end{tabular}

Whereas, on the exclusion stocks in the MSCI index showed in Table 6, there was a negative and significant AAR that happened on the day of the announcement also a day after it. Based on the result, it can be assumed that the market gives a response to the announcement of changes to the inclusion and exclusion stocks in the MSCI index. Then, there was an anomaly since significant AAR on the tenth day after the exclusion stocks announcement from the MSCI index. Furthermore, the stocks that exclude from the MSCI index showed there was a significant CAAR in the amount of $-10.46 \%$ and $-9.64 \%$ on the first and second days after the announcement of MSCI index changes.

\subsection{Volume Effects of Inclusion and Exclusion Stocks from LQ45 Index}

Table 7 showed the result of a significance test on inclusion and exclusion indexes in the LQ45 index towards stock trading volume, where the test is done to prove that the score of MVR is different than 1. It showed that the activity of 
stocks trades that include and exclude move abnormally since the index composition changes. According to Table 7, it can be referred that the stocks included in the LQ45 index have no significant MVR, whereas the stock excluded from the LQ45 index have significant MVR since the day of announcement until the fourth day after the index changes announcement. It means that the announcement of stocks excluded causing the significant changes in the stock trading volume; in other words, the market gives a response to the announcement of stocks excluded in the LQ45 index. Yet, the market does not respond to the stocks included in the LQ45 index.

Then, the graphic movement of MVR showed in Figure 5 where it proved that the day of the LQ45 index changes announcement until a day after it, there was an improvement of the MVR score whether in inclusion or exclusion stocks from the LQ45 index.

Table 7. Significance test result from MVR for inclusion and exclusion of the LQ45 Index

\begin{tabular}{|r|r|r|r|r|}
\hline \multirow{2}{*}{$\begin{array}{c}\text { Time } \\
(\mathrm{t})\end{array}$} & \multicolumn{2}{|c|}{ Inclusions } & \multicolumn{2}{c|}{ Exclusions } \\
\cline { 2 - 5 } & MVR & \multicolumn{1}{c|}{$t$-statsistic } & MVR & \multicolumn{1}{c|}{$t$-statsistic } \\
\hline-5 & 1.0739 & 0.459 & 0.7336 & $-3.022^{*}$ \\
\hline-4 & 0.8274 & -1.509 & 0.7621 & $-2.196^{*}$ \\
\hline-3 & 0.9025 & -0.397 & 0.7937 & -1.948 \\
\hline-2 & 1.0449 & 0.196 & 0.8602 & -1.233 \\
\hline-1 & 0.7861 & -1.978 & 1.1857 & 1.451 \\
\hline 0 & 1.1803 & 1.045 & 1.4144 & $2.426^{*}$ \\
\hline 1 & 1.3454 & 1.547 & 1.6469 & $3.004 *$ \\
\hline 2 & 0.8658 & -1.107 & 1.5367 & $2.136^{*}$ \\
\hline 3 & 1.2680 & 1.497 & 1.8129 & $2.663 *$ \\
\hline 4 & 1.5480 & 1.355 & 2.4814 & $2.676^{*}$ \\
\hline 5 & 1.1219 & 0.780 & 2.1243 & 1.003 \\
\hline *statistical significance at the 5\% level &
\end{tabular}

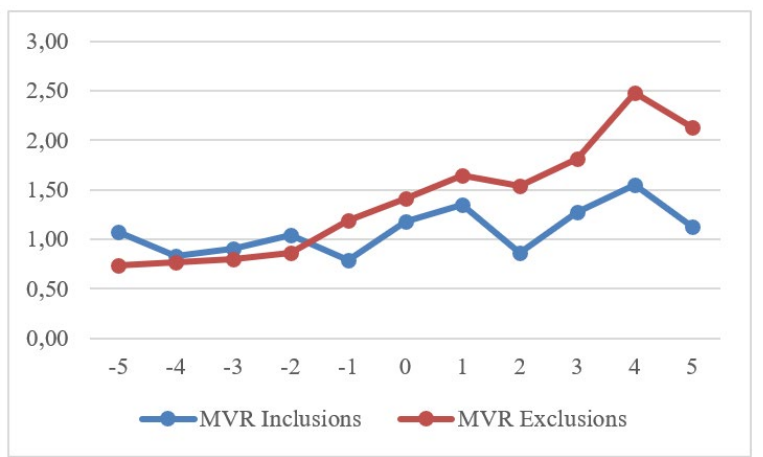

Fig. 5. Graphic movement of MVR for inclusion and exclusion stocks in the LQ45 index 


\subsection{Volume effects of inclusion and exclusion stocks from MSCI index}

The test result of MSCI index changes towards the stock trading volume was documented in Table 8 and Figure 6 . There was a significant MVR whether in the inclusion or exclusion around the announcement of MSCI index composition changes. Further, based on Table 8 and Figure 6, it can be showed that volume ratio from the stock trades tends to get significant improvement on a day after the announcement of MSCI index composition changes. According to the result obtained, it can be assumed that the market gives a response to the announcement of the changes in stocks included and excluded from the MSCI index. Where there was a significant improvement in trade volume around the date of the announcement. It also in line with the previous research conducted by Liu [17].

Table 8. Significance test result from MVR for inclusion and exclusion of the MSCI Index

\begin{tabular}{|r|r|r|r|r|}
\hline \multirow{2}{*}{$\begin{array}{c}\text { Time } \\
(\mathrm{t})\end{array}$} & \multicolumn{2}{|c|}{ Inclusions } & \multicolumn{2}{c|}{ Exclusions } \\
\cline { 2 - 5 } & MVR & $t$-statsistic & MVR & \multicolumn{1}{c|}{-statsistic } \\
\hline-10 & 1.3187 & 1.041 & 0.7939 & -1.410 \\
\hline-9 & 1.1098 & 0.617 & 1.3097 & 1.094 \\
\hline-8 & 1.2034 & 1.137 & 1.1521 & 0.344 \\
\hline-7 & 1.1138 & 0.595 & 1.2395 & 0.688 \\
\hline-6 & 1.1524 & 1.494 & 1.3710 & 1.494 \\
\hline-5 & 1.1344 & 0.990 & 1.3849 & 0.840 \\
\hline-4 & 1.7013 & 1.519 & 1.6499 & 1.324 \\
\hline-3 & 1.4511 & $2.686^{*}$ & 1.9423 & 1.956 \\
\hline-2 & 1.5354 & $2.235^{*}$ & 1.8768 & 2.053 \\
\hline-1 & 1.3833 & $2.399^{*}$ & 2.8144 & $3.119^{*}$ \\
\hline 0 & 1.5527 & $2.635^{*}$ & 1.8215 & $3.210^{*}$ \\
\hline 1 & 4.7253 & $4.716^{*}$ & 5.6067 & $5.032^{*}$ \\
\hline 2 & 2.1268 & $3.552^{*}$ & 3.9193 & $4.524^{*}$ \\
\hline 3 & 1.6069 & $2.155^{*}$ & 5.1561 & $3.899^{*}$ \\
\hline 4 & 1.6907 & $2.445^{*}$ & 3.7188 & $5.452^{*}$ \\
\hline 5 & 1.3713 & 1.728 & 4.0789 & $3.098^{*}$ \\
\hline 6 & 1.4209 & 1.590 & 3.5227 & $3.455^{*}$ \\
\hline 7 & 1.7908 & 2.104 & 3.5344 & $3.108^{*}$ \\
\hline 8 & 1.7619 & $2.355^{*}$ & 3.9003 & $4.084^{*}$ \\
\hline 9 & 1.7717 & $4.140^{*}$ & 3.2248 & $3.319^{*}$ \\
\hline 10 & 2.9072 & $3.854^{*}$ & 6.9723 & 1.726 \\
\hline
\end{tabular}

*statistical significance at the $5 \%$ level 


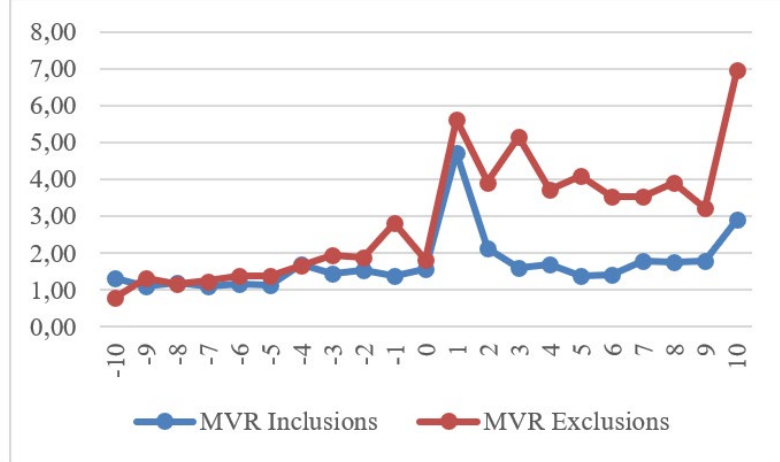

Fig. 6. Graphic movement of MVR for inclusion and exclusion stocks in the MSCI index

\section{Conclusion}

The research conducted in order to do a deep study regarding the effect of inclusion and exclusion indexes in the LQ45 index and MSCI index towards stocks return and stock trading volume. Further, there was a positive and significant abnormal return around the date of index changes announcement in the group of stocks included to the LQ45 index and MSCI index. It means that the market gives a positive response regarding the information since the market believes that it was good news. The stocks included contains information that has economic value which able to increase the value of company on investor's view; therefore, investors decided to buy stocks from the companies included to the index. On the contrary, the stocks excluded from LQ45 and MSCI index were found that negative abnormal return which significantly occurred around the date of index changes announcement. The stocks excluded from index contain information which has negative economic value that lowering the company's value, thus, the investors decided to not buy, or for investors who have excluded stocks in the index tend to sell the stocks from the company. This is caused the stocks return getting down.

Further, the stocks included in the LQ45 index did not cause any impact on the stock trading volume around the date of the announcement. It was indicated that the stock changes included in the LQ45 index did not have any response by the market since the stocks included in the index has been on the position which relatively optimal. It can be inferred that the institution which did an analysis of stock included in the LQ45 index (in case of IDX) has been done filtering, where the stock included in the LQ45 index, there was no response on the trade volume that significantly added since before including to the LQ45 index, the volume was relatively high. However, the stock trading volume around the date of the 
announcement was significantly impacting the stocks excluded in the LQ45 index. It can be concluded that the market gives a response on the stocks excluded in the LQ45 index, thus, it was significantly impacted by the stock trading volume. It caused people to assume that the fundamental or company's performance was lowering, therefore, people tend to sell their stocks.

Then, the company's stocks in Indonesia that included or excluded from the MSCI index induced a significant impact to the stock trading volume around the announcement date. Half of the investors tend to use the MSCI index because they assume that Morgan Stanley as the issuing agency of the MSCI index which an international institution that has a good reputation. The investor did sell or buy transactions when Morgan Stanley evaluating stock composition included in the MSCI index. The role of investors that use the MSCI index as a reference to determine the portfolio in Indonesia is quite influential, therefore, it induced the transaction volume which significantly changes and so does the stock prices. Normally, the fund manager or investor will evaluate the portfolio with the new MSCI index, thus, they are relative will buy the stocks. If in the MSCI index, it was found stocks with not portfolio yet, it means that the manager of investment relatively will buy the stocks. However, if there is stock in the portfolio that has been excluded from the MSCI index, it means the manager of investment will take a look at whether the holding is needed or selling the stock, it depends on the position of return than expected from them.

Based on statement above, it can be seen that the announcement of the inclusion or exclusion stock from the LQ45 and MSCI index contains information. This information is then responded by the market. Where there are a significant and insignificant response to the announcement of changes in the composition of the LQ45 and MSCI index both stock returns and stock trading volume. It shows that the Indonesian capital market is not fully efficient market.

In conclusion, the present study is limited on the announcement of stocks composition changes on LQ45 index and MSCI index for stocks listed in IDX. For the future study expected can be conducted with other occasions, besides the index composition changes that probably could be a reference for the investor in investing the capital market, therefore it helps investors to minimize the risk of loss. Specifically, for novice investors that they are not afraid to do a transaction in the capital market. If they are reluctant to transact in the capital market since their experience of having loss, thus there will be a potency of Single Investor Identification from the investors become a dormant.

Next, in order to gain the best result of the research, the next study expected not only to use the market model to estimate the expected return. However, the mean-adjusted model and market-adjusted model can be used to obtain the result's comparison towards each model. 
Acknowledgments. We express our gratitude to the Faculty of Economics and Business, the University of Indonesia especially the Master of Management Program since already provided and supported with a very well facilities, therefore we can accelerate the writing of this paper. Then, this gratitude also expressed to other parties who supported and contributed in the process of this paper that the writer might not be able to mention one by one.

\section{References}

[1] Wilkens S, Wimschulte J. Price and Volume Effects Associated with 2003's Major Reorganization of German Stock Indices. Financial Markets and Portfolio Management. 2005;19(1):61-98.

[2] Bechmann KL. Price and Volume Effects Associated with Changes in the Danish BlueChip Index: The KFX Index. Multinational Finance Journal. 2004;8(1/2):3-34.

[3] Shankar SG, Miller JM. Market Reaction to Changes in the S\&P SmallCap 600 Index. Financial Review. 2006;41(3):339-60.

[4] Hung C-W, Shiu C-Y. Trader activities, ownership, and stock price reactions to MSCI standard index changes: Evidence from Taiwan. Journal of Multinational Financial Management. 2016;36:49-63.

[5] Chen Y, Koutsantony C, Truong C, Veeraraghavan M. Stock price response to S\&P 500 index inclusions: Do options listings and options trading volume matter? Journal of International Financial Markets, Institutions and Money. 2013;23:379-401.

[6] Chen H-L, Shiu C-Y, Wei H-S. Price effect and investor awareness: Evidence from MSCI Standard Index reconstitutions. Journal of Empirical Finance. 2019;50:93-112.

[7] Ross SA, Westerfield RW, Jaffe J, Jordan BD. Corporate Finance Eleventh Edition. New York: McGraw-Hill Education; 2016.

[8] Harris L. Trading and exchanges : market microstructure for practitioners. New York: Oxford University Press; 2003.

[9] Hartono J. Teori Portofolio dan Analisis Investasi Edisi Kesebelas. Yogyakarta: BPFEYogyakarta; 2017.

[10] Fama EF. Efficient capital markets: A review of theory and empirical work. The journal of Finance. 1970;25(2):383-417.

[11] Kassim NS, Ramlee R, Kassim S. Impact of Inclusion into and Exclusion from the Shariah Index on a Stock Price and Trading Volume: An Event Study Approach. International Journal of Economics and Financial Issues. 2017;7(2):40-51.

[12] Shu P-G, Yeh Y-H, Huang Y-C. Stock Price and Trading Volume Effects Associated with Changes in the MSCI Free Indices: Evidence from Taiwanese Firms Added to and Deleted from the Indices. Review of Pacific Basin Financial Markets and Policies. 2004;7(4):47191.

[13] Chakrabarti R, Huang W, Jayaraman N, Lee J. Price and volume effects of changes in MSCI indices - nature and causes. Journal of Banking \& Finance. 2005;29(5):1237-64. 
[14] Jain PC. The Effect on Stock Price of Inclusion in or Exclusion from the S\&P 500. Financial Analysts Journal. 1987;43(1):58-65.

[15] Brown SJ, Warner JB. Using daily stock returns: The case of event studies. Journal of Financial Economics. 1985;14(1):3-31.

[16] Harris L, Gurel E. Price and Volume Effects Associated with Changes in the S\&P 500 List: New Evidence for the Existence of Price Pressures. The Journal of Finance. 1986;41(4):815-29.

[17] Liu S. Changes in the Nikkei 500: New Evidence for Downward Sloping Demand Curves for Stocks. International Review of Finance. 2000;1(4):245. 